\title{
Combining trait and state model systems of psychosis: The effect of sleep deprivation on cognitive functions in schizotypal individuals
}

\author{
Eliana Faiola ${ }^{\mathrm{a}, *}$, Inga Meyhöfer ${ }^{\mathrm{a}}$, Maria Steffens ${ }^{\mathrm{a}}$, Anna-Maria Kasparbauer ${ }^{\mathrm{a}}$, Veena Kumari ${ }^{\mathrm{b}}$, \\ Ulrich Ettinger ${ }^{\mathrm{a}, *}$ \\ a Department of Psychology, University of Bonn, Kaiser-Karl-Ring 9, Bonn 53111, Germany \\ ${ }^{\mathrm{b}}$ Centre for Cognitive Neuroscience, Department of Life Sciences, Brunel University London, Kingston Lane, Uxbridge UB8 3PH, UK
}

\section{A R T I C L E I N F O}

\section{Keywords:}

Schizophrenia spectrum

Schizotypal personality traits

Cognitive biomarkers

\begin{abstract}
A B S T R A C T
Model systems of psychosis play an important role in pathophysiology and drug development research. Schizotypal individuals display similar cognitive impairments as schizophrenia patients in several domains. Therefore, schizotypy may be interpreted as a trait model system of psychosis. In addition, experimentally controlled sleep deprivation is a putative state psychosis model that evokes subclinical psychosis-like states. We aimed to further validate these model systems by examining them in relation to central cognitive biomarkers of schizophrenia. Most of all, we were interested in investigating, for the first time, effects of their combination on cognitive function. Healthy subjects with high $(N=17)$ or low $(N=19)$ levels of schizotypy performed a cognitive task battery after one night of normal sleep and after $24 \mathrm{~h}$ of sleep deprivation. Sleep deprivation impaired performance in the go/nogo and n-back tasks relative to the normal sleep control condition. No differences between groups or interactions of group with sleep condition were found. The role of sleep deprivation as a model of psychosis is thus supported to some extent by impairments in inhibitory control. However, classical measures of cognition may be less able to detect deficits in schizotypy, in line with evidence of more basic information processing dysfunctions in schizotypy.
\end{abstract}

\section{Introduction}

Model systems of psychosis are of use in improving our understanding of pathophysiological mechanisms of the disorder and in the development of novel antipsychotic medications. One approach is to generate trait model systems, e.g., studying a surrogate population consisting of individuals scoring high on specific traits that resemble the key symptoms of psychosis (Koychev et al., 2011, 2016). Another approach is to generate state model systems, that is, temporarily inducing psychosis-like symptoms by means of behavioral or pharmacological interventions (Corlett et al., 2016; Meyhöfer et al., 2016; Murray et al., 2013).

A promising trait model system of psychosis is schizotypy, which is defined as a set of personality features closely mirroring a wide range of schizophrenic symptoms but at a subclinical level (Ettinger et al., 2014; Nelson et al., 2013). Both schizotypy and schizophrenia are characterized by a three-factor structure, including positive (e.g., magical thinking), negative (e.g., anhedonia) and disorganized (e.g., poor concentration) dimensions (Liddle, 1987; Nelson et al., 2013).
Furthermore, schizotypy and schizophrenia overlap in terms of brain structure (e.g., reduced grey matter volume in medial prefrontal and temporal areas; Ettinger et al., 2012), and brain function (e.g., reduced activation in the insula, putamen, thalamus, and other regions during prepulse inhibition; Kumari et al., 2007, 2008) as well as oculomotor control (Koychev et al., 2016; Meyhöfer et al., 2017; O'Driscoll and Callahan, 2008).

An intriguing state model system of psychosis is acute sleep deprivation (Ettinger and Kumari, 2015). Acute sleep deprivation of $>24 \mathrm{~h}$ evokes psychotomimetic states such as perceptual distortion, anhedonia, and cognitive disorganization (Meyhöfer et al., 2017; Petrovsky et al., 2014) as well as impairments typically linked to schizophrenia, such as deficits in oculomotor performance (Meyhöfer et al., 2016, 2017) and prepulse inhibition (Petrovsky et al., 2014). These findings agree with literature showing that as sleep deprivation evokes deficits in brain areas that are also affected in schizophrenia, such as decreased metabolic activity in the prefrontal cortex, the thalamus, and the basal ganglia (Shenton et al., 2001; Shepherd et al., 2012; Thomas et al., 2000, 2003).

\footnotetext{
* Corresponding authors.

E-mail addresses: eliana.faiola@uni-bonn.de (E. Faiola), Inga.Meyhoefer@ukmuenster.de (I. Meyhöfer), maria.steffens@uni-bonn.de (M. Steffens), kasparbauer@uni-bonn.de (A.-M. Kasparbauer), Veena.Kumari@brunel.ac.uk (V. Kumari), ulrich.ettinger@uni-bonn.de (U. Ettinger).
} 
The validity of such model systems is commonly tested by investigating deficiencies that are widely considered valid signatures of psychosis. One of the most firmly established markers of schizophrenia is a pattern of deficits in various cognitive functions, including response inhibition, working memory, sustained attention, verbal learning, problem solving and verbal fluency (Heinrichs and Zakzanis, 1998; Mesholam-Gately et al., 2009; Schaefer et al., 2013; Snitz et al., 2006). Of note, these findings concern mainly the cognitive deficit subtype of schizophrenia, which displays pervasive impairments across the majority of cognitive functions, and not for the cognitively spared subtype, where cognitive functions are only slightly affected (Jablensky, 2006).

In support of schizotypy and sleep deprivation as model systems of psychosis, the cognitive deficits observed in psychotic patients also typically occur in high schizotypes (as compared to low schizotypes, e.g., Bergida and Lenzenweger, 2006; Chan et al., 2011; Giakoumaki, 2012) and as a consequence of acute sleep deprivation (as compared to normal sleep conditions, e.g., Drummond et al., 2006; Joo et al., 2012; Labelle et al., 2015), albeit at lower levels.

Impairments in response inhibition (i.e., the ability to suppress an inappropriate but prepotent response to a stimulus; Friedman and Miyake, 2004) in high schizotypes have been reported, for example, by means of a higher error rate in the go/nogo task (Kaczorowski et al., 2009); however, this applies only to positive-but not negative or disorganized - schizotypy (Kaczorowski et al., 2009; Peters et al., 1994). Likewise, response inhibition on go/nogo tasks is reduced after sleep deprivation (Drummond et al., 2006; Chuah et al., 2006; but see Acheson et al., 2007). Working memory is worse in high schizotypes (for reviews, see Chun et al., 2013; Giakoumaki, 2012). This result has been reported from studies with different measures of working memory, such as accuracy in the 3-back task (Kerns and Becker, 2008) or the Wechsler letter-number sequencing (Matheson and Langdon, 2008). Working memory (e.g., accuracy in the n-back task) also decreases severely after sleep deprivation (Choo et al., 2005), in line with studies demonstrating the importance of sleep for working memory in children and adolescents (Kopasz et al., 2010). Sustained attention (frequently assessed with the Continuous Performance Test) is poorer in high schizotypes; again, however, this is limited to positive schizotypy (Bergida and Lenzenweger, 2006; Lenzenweger and Gold, 2000; Lenzenweger, 2001; Obiols et al., 1999). This fundamental cognitive function also declines after sleep deprivation (Ikegami et al., 2009; Joo et al., 2012; Labelle et al., 2015). Verbal learning (measured with the amount of correctly learned words in the California Verbal Learning Test or the Wechsler logical memory test) appears to be reduced in high schizotypes (Chan et al., 2011; Palacio et al., 2006), although there are some inconsistent findings (Aguirre et al., 2008; Lenzenweger et al., 2000). Similarly, the effect of sleep deprivation on verbal learning is subject to debate (Drummond et al., 2000; Karlsson et al., 2005). Problem solving appears not to differ between high and low psychometric schizotypes; reaction times and accuracy in tasks like the Tower of London or the Stockings of Cambridge tasks were found to be identical in low and high schizotypes (Langdon and Coltheart, 1999; Laws et al., 2011). However, impairments have been observed in adolescents with a diagnosis of schizotypal personality disorder (Diforio et al., 2000). Sleep deprivation also has a detrimental effect on problem solving (Horne, 1988; Killgore et al., 2009). Verbal fluency (measured, e.g., with the task to name as much animals as possible within one minute) is decreased in high schizotypes, especially those scoring high on the positive dimension (Krabbendam et al., 2005), and after sleep deprivation (Harrison and Horne, 1997, 1998).

Overall, these findings indicate that both schizotypy and sleep deprivation involve psychosis-like cognitive deficits. However, two recent meta-analyses have revealed that cognitive impairments in schizotypal individuals are somewhat inconsistent and effect sizes tend to be in the small range (Chun et al., 2013; Steffens et al., 2018). Therefore, and given the promising evidence from state model systems (Ettinger and Kumari, 2015; Meyhöfer et al., 2016; Petrovsky et al., 2014), the question arises whether the cognitive deficits observed in psychosis can be approximated more closely by an interaction of schizotypy as a trait and sleep deprivation as a state model system. Surprisingly, most of the previous studies have tested the effect of either the schizotypy or the sleep deprivation model. A recent study by Meyhöfer et al. (2017), however, supports the importance of combining these models, as effects of sleep deprivation on smooth pursuit gain, a prominent oculomotor biomarker of psychosis, were found to be more pronounced in schizotypals than controls.

Therefore, we first aimed at replicating previous findings of cognitive deficits in high (as compared to low) schizotypy and after sleep deprivation (as compared to normal sleep). Additionally, we probed for interactions of the two model systems in cognitive performance. Generally, we expected the strongest impairment to occur when high schizotypy was coupled with sleep deprivation. As the majority of previous studies reported cognitive deficits in positive (rather than negative or disorganized) schizotypy, we restricted our sample to individuals scoring high on this specific dimension. In light of the broad set of cognitive impairments in psychosis (Fioravanti et al., 2012), we tested participants' performance on six different tasks tapping into a variety of cognitive functions: response inhibition, working memory, sustained attention, verbal learning, problem solving and verbal fluency.

\section{Methods}

\subsection{Recruitment and selection of participants}

Participants were recruited from the general population via flyers and social media platforms that linked to an online version of the Oxford-Liverpool Inventory of Feelings and Experiences short form (OLIFE, German version, Grant et al., 2013). The Unusual Experiences (UE) and Introvertive Anhedonia (IA) scales for measuring positive and negative schizotypy were used for assignment to the two groups. A total of $N=5006$ subjects filled out the questionnaire. Subjects were assigned to the schizotypy group if they scored $\geq 1.25 \mathrm{SD}$ above the same sex mean UE and $\leq 0.5$ SD below the same sex mean IA score. This ensured to include only schizotypes with mainly positive schizotypy traits. Assignment to the control group required a score of $\leq 0.5 \mathrm{SD}$ below the same sex mean UE and IA score. Eligible subjects (both schizotypes and controls with the required scores in the O-LIFE) were invited to a telephone screening. If they replied to the invitation, they were screened for the exclusion criteria of age $<18$ and $>50$, native language other than German, any present Axis I disorder or past or present psychotic disorder (MINI International Neuropsychiatric Interview German Version 5.0.0, Ackenheil et al., 1999), a first-degree relative with a psychotic disorder, visual impairments (except for glasses/ lenses) or eye surgery, regular medication intake (except for contraceptives or vitamins), any current sleep disorder or engagement in shift working and current alcohol (ACE AL5500) or drug consumption (DrugScreen Multi 5T, nal von minden $\mathrm{GmbH}$ ). Only a small proportion of the $N=5006$ participants who filled out the O-LIFE participated in the telephone screening; this was because only a minority of participants reached the required O-LIFE scores, and some of those did not provide any contact data so that it was not possible to invite them to participate in the follow-up study. Moreover, a high number of participants did not reply to the initial invitation to the follow-up study. The study was approved by the ethics committee of the Department of Psychology, University of Bonn, and all participants provided written informed consent. Participant compensation was course credits (for psychology students) or $80 €$ (for other participants).

\subsection{Study procedure}

After completion of the O-LIFE, suitable participants were screened for above exclusion criteria via telephone, followed by two laboratory 
sessions that took place at intervals of one week. In both study conditions (sleep deprivation and normal sleep night), participants arrived at the laboratory at 8:30 PM. They had been instructed well in advance not to consume any caffeine from 5 PM until the end of the study session. When arrived at the laboratory, participants first completed a battery of state inventories, among them the Psychotomimetic States Inventory (PSI, Mason et al., 2008). During the normal sleep night, participants slept in the laboratory from 11:00 PM to 6:55 AM. In the sleep deprivation night, participants stayed awake during the whole night in the presence of an examiner. Participants were allowed to read, watch movies or play board games. In addition, they completed demographic questionnaires and the Mehrfachwahl-Wortschatz-Intelligenztest, Version B (a measure of verbal intelligence, Lehrl, 2005) and went for four 15-minutes walks at 10:30 PM, 1:30 AM, 4:30 AM and 6:30 AM. They were not allowed to eat or drink except for water. In both study conditions, a light breakfast at 7:30 AM was followed by a cognitive and oculomotor test battery, beginning at 8:00 AM and lasting about $3.5 \mathrm{~h}$, followed by another completion of the aforementioned state questionnaires.

\subsubsection{Cognitive tasks}

Flow charts and details of some of the tasks are provided in the Supplementary Material. Computer-based tasks were conducted on a 19-inch LCD monitor (Hyundai X93W, $1440 \times 900$ resolution) at a distance of $70 \mathrm{~cm}$ from participants. They were implemented using Presentation Version 18.1 (Neurobehavioral Systems, Inc., Berkeley, CA, USA). The order of tasks was randomized for each participant and held constant throughout both study conditions. To minimize training effects from the first to the second laboratory session, parallel forms of each task were applied.

Response inhibition was measured with the go/nogo task (GNG). Participants were instructed to respond by pressing the space bar when the go-stimulus was shown and to withhold the response when the nogo-stimulus was presented. The dependent variables were the percentage of errors on nogo-trials (commission errors) as well as the mean reaction time (MRT) of correct go-trials.

Working memory was assessed with the $n$-back task (modified from Ettinger et al., 2011). Participants were required to press a key corresponding to the position of a dot that appeared at one of four possible positions on the screen. When a dot was presented, participants either had to respond immediately and as quickly as possible to this given dot (0-back condition) or to the dot that had been presented one, two or three trials before (1-, 2-, or 3-back condition). Thus, in the 1-, 2-, and 3-back conditions, participants had to keep the position of the stimuli in working memory. Dependent variables were the percentage and the MRT of correct responses.

Sustained attention was examined using the Continuous Performance Test (CPT)—identical pairs version (Cornblatt et al., 1988). Participants had to respond as quickly as possible to four-digit stimuli when an identical pair showed up, i.e. when there was an exact repetition of digits (e.g., 9004 followed by 9004). Catch trials consisted of pairs of stimuli where one of the two middle digits had been exchanged (e.g. 8617-8657). The remaining stimuli were singletons, not resembling a previous or following stimulus, randomly interleaved amongst identical pairs and catch pairs. The parameter $c$ measuring response bias and the sensitivity index $d$ ', as well as the MRT of correct responses (responses to identical pairs) were analyzed.

Verbal learning was studied by means of the California Verbal Learning Test (CVLT, Niemann et al., 2008). Over five learning rounds, participants listened to a list of 16 words from four categories and had to repeat it afterwards. Learning rounds were followed by a second, interfering word list that had to be recalled once. Subsequently, participants were asked to recall words from the first list immediately and again after a 30-minutes-delay. Each recall (immediate and delayed) was implemented first without and then with cues that hinted at the four categories (e.g., food as cue for the words eggs, cheese, coffee, ham).
Dependent variables were the total number of correct responses (during the five learning rounds and the immediate and delayed recall with and without cues), the consistency (the number of repeatedly recalled words during the first five rounds) and the learning curve (the increase of recalled words from round one to round five).

Problem solving ability was investigated with the computerized Tower of London task (TOL, modified version from Shallice, 1982, see also Kempton et al., 2011). Participants were required to relocate balls from an initial position to a target position within three tubes of different lengths in as few moves as possible, whereby only one ball at a time was allowed to be moved. Movements of balls had to be kept in mind and one of four possible answers (one, two, three or four movements) had to be chosen. Performance was measured by calculating the percentage and the MRT of correct responses.

Verbal fluency was assessed by the Regensburger Wortflüssigkeitstest ( $R W T$, Aschenbrenner et al., 2000) which required participants to name, within two minutes, as many words as possible beginning with a certain letter (lexical condition) or deriving from a certain category (semantic condition). In the shifting condition, the task was to name as many words as possible while shifting between two different initial letters (lexical shifting condition) or between two different categories (semantic shifting condition). The number of correct words was analyzed for each of the four conditions.

\subsubsection{Psychotomimetic states}

Psychotomimetic states were measured using the Delusional Thinking, Perceptual Distortion, Cognitive Disorganization, Anhedonia, Mania, and Paranoia subscales of the PSI.

\subsection{Statistical analyses}

Statistical analyses were performed using IBM SPSS Statistics 24.0 (IBM, Armonk, NY, USA). All dependent variables were tested for normality of distribution. Variables were transformed using log transformation when normality of distribution was violated, which was examined with the Shapiro-Wilk-Test (Shapiro and Wilk, 1965), skewness and outliers. Levene's Test was used to test homogeneity of variance (Glass, 1966) and violations of the assumption of sphericity were adjusted using Greenhouse Geisser correction (Jennings, 1987). Effect sizes for analyses of variance (ANOVAs) were estimated using partial eta-squared (Cohen, 1973).

Inferential statistical analyses were carried out with significance set at $p<.05$. Each cognitive task was analyzed separately using ANOVA. For each task, the ANOVA included the within-subjects factor study condition (normal sleep night, sleep deprivation night) and the betweensubjects factor group (schizotypes, controls). For certain tasks, the following factors were added: the within-subjects factor load was added for the TOL $(1,2,3$, and 4 required movements) and the n-back task (0, 1,2 , and 3 trials back). The RWT included the within-subjects factors shifting (shifting, no shifting) and fluency type (lexical, semantic). Significant interactions were followed up with two-tailed $t$-tests using Bonferroni-Holm correction (Holm, 1979). Order (sleep deprivation first vs. sleep first) was initially included as an additional betweensubjects factor in all ANOVAs but then dropped as it did not interfere with the reported results. For full summaries of ANOVAs see Supplementary Tables $2-4$.

For the present sample, the influence of schizotypy and sleep deprivation on psychotomimetic states, as measured by the PSI scales, has previously been investigated and reported elsewhere (Meyhöfer et al., 2017). Psychotomimetic states increased after sleep deprivation (compared to scores after a normal sleep night) on the subscales Perceptual Distortion, Cognitive Disorganization and Anhedonia. Scores on Delusional Thinking, Perceptual Distortion and Mania were higher in the schizotypy group than in the control group. Here, to examine whether cognitive functions were related to psychotomimetic states, we computed correlations between PSI scores and performance in the cognitive 
Table 1

Descriptive statistics of the sample by group.

\begin{tabular}{|c|c|c|c|c|}
\hline Variable & Schizotypes $(n=17)$ & Controls $(n=19)$ & Total Sample $(n=36)$ & Statistics* \\
\hline Mean age (years) (SD) & $26.82(7.91)$ & $24.63(5.42)$ & $25.67(6.70)$ & $T_{(34)}=0.98, p=.33$ \\
\hline Gender ( $n$, female/male) & $12 / 7$ & $12 / 5$ & $24 / 12$ & $\chi_{(1)}^{2}=0.22, p=.64$ \\
\hline Mean years of education (SD) & $17.18(2.88)$ & $16.37(4.06)$ & $16.75(3.52)$ & $T_{(34)}=0.68, p=.50$ \\
\hline Mean verbal IQ (SD) & $110.88(15.07)$ & 111.63 (13.98) & $111.28(14.30)$ & $T_{(34)}=0.16, p=.88$ \\
\hline Mean UE score (SD) & $9.94(0.97)$ & $1.79(0.98)$ & $5.64(4.24)$ & $T_{(34)}=25.13, p<.001$ \\
\hline Mean IA score (SD) & $1.12(0.93)$ & $0.68(0.48)$ & $0.89(0.75)$ & $T_{(34)=1.79, p=.10}$ \\
\hline Mean CD score (SD) & $7.65(2.80)$ & $3.58(2.84)$ & $5.50(3.44)$ & $T_{(34)=}-4.35, p<.001$ \\
\hline
\end{tabular}

Notes. SD, Standard Deviation; UE, Unusual Experiences; IA, Introvertive Anhedonia; CD, Cognitive Disorganization.

* Comparison between schizotypes and controls.

tasks. To restrict the number of correlations, we performed the analysis only on variables that were affected by sleep deprivation (Meyhöfer et al., 2017), namely GNG errors of commission, n-back rate of correct responses and PSI subscales Perceptual Distortion, Cognitive Disorganization and Anhedonia. To compute the correlations, change scores were calculated (sleep deprivation morning-normal sleep night morning).

\section{Results}

\subsection{Sample description}

Thirty-six subjects met inclusion criteria and participated in the study, among them 17 high schizotypes and 19 control subjects (Table 1). TOL data from two high schizotypes and n-back data from one control subject were eliminated due to apparent failure to understand the task. One control subject was excluded for the GNG task as the MRT of correct go-trials deviated 5 SD from the mean. Descriptive statistics of cognitive performance and the PSI can be found in Tables 2 and 3, respectively. Figures for all cognitive tasks are provided in Supplementary Figs. 5-15.

\subsection{Cognitive tasks}

\subsubsection{Go/nogo task}

For errors of commission, a main effect of study condition revealed a higher error rate after a night of sleep deprivation than after a night of normal sleep $\left(F_{(1,33)}=14.06 ; p=.001, \eta_{\mathrm{p}}{ }^{2}=0.30\right.$; Fig. 1$)$. No effect of group and no interaction effect between group and study condition was found (all $p>$.17). For MRT of correct go-trials, no main or interaction effects were found (all $p>.22$ ).

\subsection{2. $N$-back task}

For rate of correct responses, a main effect of study condition revealed a higher rate after the night of normal sleep than after sleep deprivation $\left(F_{(1,33)}=5.54 ; p=.03 ; \eta_{\mathrm{p}}{ }^{2}=0.14\right.$; Fig. 2$)$. In addition, a main effect of load showed that fewer correct responses were given in trials with a higher number of steps back $\left(F_{(2.28,75.28)}=209.68\right.$; $\left.p<.001 ; \eta_{\mathrm{p}}{ }^{2}=0.86\right)$. After Bonferroni-Holm correction, post-hoc paired-sample $t$-tests were significant between all load levels: more correct responses were given in the 0-back condition compared to the 1 back $\left(t_{(34)}=9.66, p<.001, d=2.23\right)$, the 2-back $\left(t_{(34)}=16.13\right.$, $p<.001, d=3.78)$ and the 3 -back condition $\left(t_{(34)}=27.53, p<.001\right.$, $d=6.18$ ). Also, a higher percentage of correct responses was found for the 1-back compared to the 2-back $\left(t_{(34)}=7.66, p<.001, d=1.04\right)$ and the 3-back condition $\left(t_{(34)}=11.80, p<.001, d=1.80\right)$. Furthermore, participants gave more correct responses in the 2-back than in the 3-back condition $\left(t_{(34)}=6.13, p<.001, d=0.65\right)$. No main effect of group and no interaction effects between group, study condition and load were found (all $p>.23$ ). For the MRT of correct responses, no main effect of study condition, group or load and no interactions between these factors were found (all $p>.06$ ).

\subsubsection{Continuous Performance Test}

For all dependent variables, no main effect of study condition or group and no interaction between these factors was found (c: all $p>.06 ; \mathrm{d}$ ': all $p>.09$; MRT: all $p>.35$ ).

\subsubsection{California Verbal Learning Test}

For all dependent variables, no main effect of study condition or group and no interaction between these factors was found (learning curve: all $p>.25$; correct responses: all $p>.51$; consistency: all $p>$.35).

\subsubsection{Tower of London task}

An effect of load was found for MRT of correct responses $\left(F_{(2.03}\right.$, 64.95) $=416.48, p<.001, \eta_{\mathrm{p}}{ }^{2}=0.93$ ). The MRT increased with a higher number of required movements. Post-hoc paired-sample $t$-tests were significant between all task conditions: MRT for correct responses was lower in the 1-movement condition compared to the 2-movements $\left(t_{(33)}=-13.87, \quad p<.001, \quad d=-1.52\right), \quad$ the 3 -movements $\left(t_{(33)}=-20.05, p<.001, d=-2.41\right)$ and the 4-movements condition $\left(t_{(33)}=-25.62, p<.001, d=-3.81\right)$. Also, a lower MRT of correct responses was found for the 2-movements compared to the 3-movements $\left(t_{(33)}=-10.21, p<.001, d=-0.86\right)$ and the 4-movements condition $\left(t_{(33)}=-21.75, p<.001, d=-2.31\right)$. Furthermore, participants needed less time in the 3-movements than in the 4-movements condition $\left(t_{(33)}=-18.26, p<.001, d=-1.48\right)$. No other main or interaction effects were significant (all $p>.36$ ). The percentage of correct responses was not further analyzed as the error rate was very low, especially in the 1-movement condition.

\subsubsection{Regensburger Wortflüssigkeitstest}

There was a main effect of fluency type, indicating a higher number of correct responses in the semantic condition than the lexical condition $\left(F_{(1,34)}=161.22, p<.001, \eta_{\mathrm{p}}{ }^{2}=0.83\right)$. A main effect of shifting showed that shifting between starting letters or categories led to fewer correct responses than no shifting $\left(F_{(1,34)}=73.92, p<.001\right.$, $\left.\eta_{\mathrm{p}}{ }^{2}=0.69\right)$. Furthermore, an interaction effect between these factors was found $\left(F_{(1,34)}=328.18, p<.001, \eta_{\mathrm{p}}{ }^{2}=0.91\right)$. For the lexical condition, a post-hoc paired-sample $t$-test revealed that shifting led to more correct responses than not shifting $\left(t_{(35)}=-7.42, p<.001\right.$, $d=-0.91$ ). For the semantic condition, shifting led to fewer correct responses than not shifting $\left(t_{(35)}=16.22, p<.001, d=2.19\right)$. When required to shift, participants generated more correct responses in the lexical condition $\left(t_{(35)}=2.55, p=.02, d=0.40\right.$ ). When not required to shift, they generated more correct responses in the semantic condition $\left(t_{(35)}=-19.20, p<.001, d=-2.71\right)$. However, there were no main effects of study condition or group and no interaction effects between any of these factors (all $p>.10$ ).

\subsection{Correlations between cognitive performance and psychotomimetic} states

No significant correlations were found between the change scores of 
Table 2

Descriptive statistics of cognitive measures.

\begin{tabular}{|c|c|c|c|c|}
\hline Task / Variable & $\begin{array}{l}\text { Schizotypes }(n=17) \\
\text { sleep }\end{array}$ & wake & $\begin{array}{l}\text { Controls }(n=19) \\
\text { sleep }\end{array}$ & wake \\
\hline \multicolumn{5}{|l|}{ Go/nogo task } \\
\hline errors of commission (\%) & $14.85(9.33)$ & $22.65(13.65)$ & $12.36(8.44)$ & $20.26(22.80)$ \\
\hline MRT of correct responses (ms) & $341.62(34.89)$ & $352.29(30.66)$ & $344.75(32.31)$ & $345.52(39.03)$ \\
\hline \multicolumn{5}{|l|}{ N-back task } \\
\hline \multicolumn{5}{|l|}{ correct responses (\%) } \\
\hline 0-back & $97.98(2.39)$ & $91.45(10.50)$ & 98.68 (1.19) & $96.46(6.58)$ \\
\hline 1-back & 70.39 (19.57) & $68.43(19.44)$ & $66.14(19.87)$ & $63.95(19.91)$ \\
\hline 2-back & $54.73(22.82)$ & $46.64(18.89)$ & $50.56(16.71)$ & $47.56(19.19)$ \\
\hline 3-back & $45.93(17.02)$ & $38.01(16.77)$ & $40.38(13.35)$ & $36.13(11.48)$ \\
\hline \multicolumn{5}{|l|}{ MRT of correct responses (ms) } \\
\hline 0-back & $405.79(73.08)$ & $423.99(63.31)$ & $398.84(54.91)$ & $407.70(56.90)$ \\
\hline 1-back & $369.04(150.10)$ & $355.00(162.03)$ & $372.38(159.80)$ & $335.51(189.94)$ \\
\hline 2-back & $419.09(167.42)$ & $391.51(129.15)$ & $401.18(158.53)$ & 414.59 (183.24) \\
\hline 3-back & $399.31(179.83)$ & $397.54(118.16)$ & $402.40(173.54)$ & $493.50(217.14)$ \\
\hline \multicolumn{5}{|l|}{ Continuous Performance Test } \\
\hline$c$ & $-0.01(0.41)$ & $0.15(0.39)$ & $0.10(0.27)$ & $0.08(0.43)$ \\
\hline$d^{\prime}$ & $2.71(0.92)$ & $2.31(0.95)$ & $2.72(0.93)$ & $2.62(0.80)$ \\
\hline MRT of correct responses (ms) & $415.25(92.47)$ & $428.92(74.73)$ & $423.19(81.29)$ & $421.39(73.62)$ \\
\hline \multicolumn{5}{|l|}{ California Verbal Learning Test } \\
\hline learning curve & $1.49(0.60)$ & $1.64(0.71)$ & $1.57(0.44)$ & $1.41(0.44)$ \\
\hline correct responses ( $n$ ) & $116.82(14.24)$ & $115.76(21.17)$ & $119.11(14.62)$ & 119.95 (13.02) \\
\hline consistency & $89.84(6.61)$ & $89.33(10.65)$ & $91.96(5.26)$ & $91.07(6.18)$ \\
\hline \multicolumn{5}{|l|}{$\begin{array}{l}\text { Tower of London task } \\
\text { correct responses (\%) }\end{array}$} \\
\hline 1 movement & $98.22(3.96)$ & $98.67(2.76)$ & $98.25(3.75)$ & $98.60(3.57)$ \\
\hline 2 movements & $92.44(8.68)$ & 88.89 (11.17) & $96.14(7.80)$ & $95.79(5.54)$ \\
\hline 3 movements & $95.11(5.33)$ & $86.22(16.61)$ & $91.23(11.12)$ & $88.78(11.34)$ \\
\hline 4 movements & $92.44(10.04)$ & $78.22(25.26)$ & $94.39(6.39)$ & $85.26(26.81)$ \\
\hline \multicolumn{5}{|l|}{ MRT of correct responses (s) } \\
\hline 1 movement & $3.72(1.24)$ & $3.94(1.33)$ & $3.56(0.99)$ & $3.94(1.63)$ \\
\hline 2 movements & $5.61(2.42)$ & $5.80(2.89)$ & $4.79(1.38)$ & $5.37(2.04)$ \\
\hline 3 movements & $7.01(3.29)$ & $6.55(2.72)$ & $5.89(1.37)$ & $6.49(2.07)$ \\
\hline 4 movements & $9.79(3.52)$ & $9.06(3.11)$ & $8.85(3.43)$ & $9.52(3.53)$ \\
\hline \multicolumn{5}{|c|}{$\begin{array}{l}\text { Regensburger Wortflüssigkeitstest } \\
\text { correct responses }(n)\end{array}$} \\
\hline lexical no shifting & $20.00(5.96)$ & $21.76(7.93)$ & $19.42(5.93)$ & $18.89(5.20)$ \\
\hline lexical shifting & $24.71(7.06)$ & $25.76(7.42)$ & $24.68(5.05)$ & $25.00(4.53)$ \\
\hline semantic no shifting & $36.47(11.38)$ & $38.94(7.60)$ & $39.37(6.80)$ & $39.74(8.21)$ \\
\hline semantic shifting & $22.41(4.86)$ & $23.71(4.55)$ & $22.84(3.52)$ & $23.26(4.97)$ \\
\hline
\end{tabular}

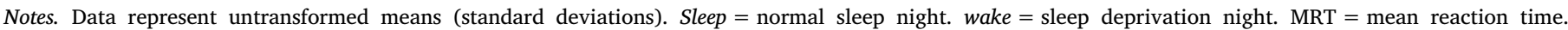
$n=$ number. $\mathrm{ms}=$ milliseconds. Deviating sample size in go/nogo and n-back task (18 controls) and Tower of London task (15 schizotypes).

GNG errors of commission, n-back rate of correct responses and PSI subscales Perceptual Distortion, Cognitive Disorganization and Anhedonia (all $p>$.07).

\section{Discussion}

In the present study, we aimed to validate sleep deprivation and schizotypy as putative models of psychosis by replicating their effects on cognitive performance. A particular goal was to examine potential interaction effects of schizotypy and sleep deprivation on measures of cognitive abilities. We expected that a combination of these two model systems would evoke stronger cognitive impairments than each model system by itself (Meyhöfer et al., 2017). Participants in groups of high versus low levels of schizotypy completed a range of cognitive tests known to be sensitive to schizophrenia spectrum effects, both after a night of sleep deprivation and after a night of normal sleep.

\subsection{Effects of sleep deprivation}

Sleep deprivation decreased performance in tasks measuring response inhibition (GNG task) and working memory (n-back task). The results of the GNG task implicate that after sleep deprivation, subjects had greater difficulties inhibiting the prepotent response of pressing a button in rare nogo trials. This finding supports the validity of sleep

Table 3

Descriptive statistics of the Psychotomimetic States Inventory (PSI).

\begin{tabular}{|c|c|c|c|c|c|c|c|c|}
\hline \multirow[t]{2}{*}{ Scale } & \multicolumn{2}{|c|}{$\begin{array}{l}\text { Schizotypes }(n=17) \\
\text { sleep }\end{array}$} & \multicolumn{2}{|l|}{ wake } & \multicolumn{2}{|c|}{$\begin{array}{l}\text { Controls }(n=19) \\
\text { sleep }\end{array}$} & \multirow{2}{*}{$\begin{array}{l}\text { wake } \\
\text { evening }\end{array}$} & \multirow[b]{2}{*}{ morning } \\
\hline & evening & morning & evening & morning & evening & morning & & \\
\hline Delusional Thinking & $7.94(3.78)$ & $5.88(4.28)$ & $7.47(4.60)$ & $6.59(5.41)$ & $1.32(1.80)$ & $0.89(1.76)$ & $1.42(2.80)$ & $0.89(2.77)$ \\
\hline Perceptual Distortion & $5.76(4.68)$ & $4.76(3.29)$ & $6.12(4.51)$ & $7.94(4.70)$ & $1.11(2.26)$ & $1.00(2.00)$ & $1.05(1.96)$ & $1.32(2.45)$ \\
\hline Cognitive Disorganization & $10.85(6.15)$ & $9.47(4.74)$ & $9.94(6.07)$ & $14.76(4.72)$ & $3.74(3.97)$ & $2.84(3.13)$ & $3.63(4.10)$ & $5.42(5.24)$ \\
\hline Anhedonia & $5.53(2.58)$ & $4.76(2.39)$ & $4.71(2.87)$ & $6.41(3.57)$ & $2.55(2.72)$ & $1.87(2.38)$ & $2.32(2.14)$ & $3.05(3.44)$ \\
\hline Mania & $6.06(3.38)$ & $4.47(2.85)$ & $5.74(3.64)$ & $5.53(3.54)$ & $2.47(1.81)$ & $2.05(1.47)$ & $2.47(2.12)$ & $2.00(1.63)$ \\
\hline Paranoia & $5.59(4.40)$ & $2.76(3.91)$ & $4.97(3.70)$ & $3.35(2.91)$ & $2.00(3.23)$ & $0.89(1.52)$ & $2.16(3.04)$ & $1.05(2.09)$ \\
\hline
\end{tabular}

Notes. Data represent untransformed means (standard deviations). $n=$ number. Sleep $=$ normal sleep night. Wake $=$ sleep deprivation night. 


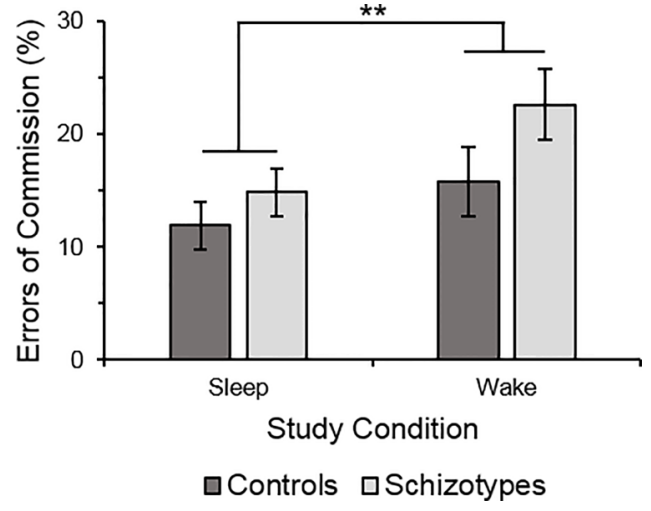

Fig. 1. Effect of study condition on go/nogo errors of commission. The main effect of study condition on go/nogo errors of commission indicates a higher error rate after a night of sleep deprivation than after a night of normal sleep $\left({ }^{* *} p<.01\right)$. Sleep $=$ normal sleep night. Wake $=$ sleep deprivation night. Error bars indicate standard errors.

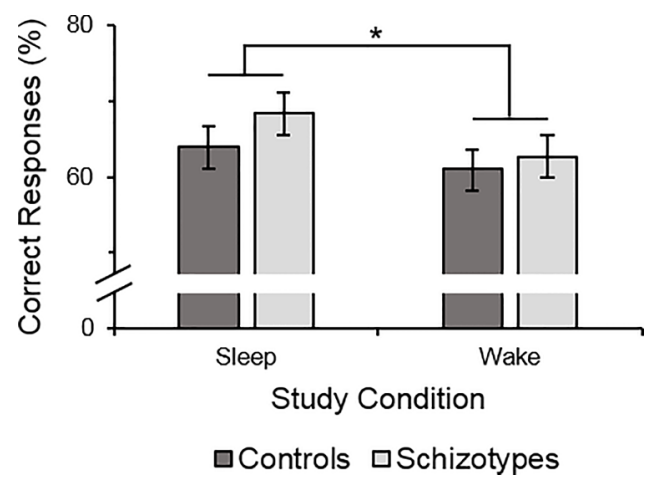

Fig. 2. Effect of study condition on the percentage of correct responses in the nback task. The main effect of study condition on n-back percentage of correct responses indicates fewer correct responses after a night of sleep deprivation than after a night of normal sleep $\left({ }^{*} p<.05\right)$. Sleep $=$ normal sleep night. Wake $=$ sleep deprivation night. Error bars indicate standard errors.

deprivation as a model system of psychosis, particularly in combination with measures of inhibition (Ettinger and Kumari, 2015), as schizophrenia patients tend to perform worse on GNG tasks than healthy controls (for meta-analyses see Minzenberg et al., 2009, Schaefer et al., 2013). The finding of impaired inhibitory control extends to different measures of response inhibition, such as the stop-signal task (for a meta-analysis, see Lipszyc and Schachar, 2010; however, see Ettinger et al., 2017).

On the n-back task, participants committed more errors after sleep deprivation than after a normal sleep night. However, this effect was observed for all levels of load, including the 0-back condition. This pattern is in line with previous studies reporting a load-independent increment in n-back errors after sleep deprivation (e.g., Choo et al., 2005; Smith et al., 2002). It should be noted, however, that these findings should be interpreted somewhat cautiously: The 0-back condition does not involve working memory (which the n-back task is designed to assess) because participants simply respond as quickly as possible to an imperative stimulus. What is consistently needed in all conditions, however, is a certain level of attention to ensure sufficient processing of the stimulus to subsequently respond to or store it. It is, therefore, questionable whether an increase in errors in all n-back conditions reflects an effect of sleep deprivation on working memory. Instead, the general reduction in the rate of correct responses might indicate that sleep deprivation decreases the overall level of attention. For schizophrenia patients, previous studies have not demonstrated such a generalized effect on overall task performance, but rather a selective impairment in working-memory related performance (i.e., in the high load conditions; see, e.g., Callicott et al., 1998; Krieger et al., 2005). This indicates that sleep deprivation and psychosis, while clearly overlapping in terms of affecting performance on the same tasks, might not impair the exact same cognitive processes underlying overt task behaviour. Clearly, this issue requires further scrutiny in additional investigations.

It is important to mention that impairments in working memory and response inhibition are not exclusively found in schizophrenia patients but also in several other psychiatric disorders, such as attention-deficit/ hyperactivity disorder (Wright et al., 2014) and obsessive compulsive disorder (e.g., van der Wee et al., 2003). Therefore, the conclusions of our findings regarding model systems of psychosis have to be drawn with caution. However, those disorders are not associated with sleepwake and circadian rhythm disturbances as strongly as schizophrenia (Boivin, 2000), where the majority of patients show disturbances ranging from excessive to highly irregular and fragmented sleep, prolonged sleep latency, and poorer sleep efficiency (Boivin, 2000; Wulff et al., 2012). These findings suggest a strong relationship between sleep deprivation and features of psychosis.

The decline in n-back performance after sleep deprivation is in line with brain activity reductions in sleep deprived participants during working memory tasks. Working memory performance is usually associated with a network of prefrontal, occipital and parietal regions (Mu et al., 2005; Olesen et al., 2004; Pessoa et al., 2002). Sleep deprivation has been reported to elicit reduced activity in those brain circuits during working memory (Chee et al., 2006; Choo et al., 2005; Habeck et al., 2004), explaining why sleep deprivation impairs performance. As activity reductions in the mentioned areas are also relevant for attentional processes (Thomas et al., 2000), this may also explain why we found an overall decrease of n-back task performance. Likewise, findings on neural mechanisms of response inhibition and how they are affected by sleep deprivation are in accordance with our results; sleep deprivation has been observed to reduce activity in the ventrolateral prefrontal cortex, the insula and the anterior cingulate, brain regions that are essential for the implementation of response inhibition (Chuah et al., 2006; Wager et al., 2005).

The detrimental effects of sleep deprivation on GNG and n-back performance that were observed in the present study applied only to accuracy, not to speed. This is relevant in two different regards: first, it clarifies that participants indeed performed worse after sleep deprivation and did not simply shift in how they weighted speed and accuracy during the task (see Wickelgren, 1977). Thus, sleep deprivation indeed impairs cognitive functions rather than merely resulting in a change in strategy. Second, several studies with schizophrenia patients have shown the same pattern of decreased accuracy, yet unaffected speed in GNG and n-back tasks (e.g., Callicott et al., 2003; Kiehl et al., 2000; Perlstein et al., 2003).

In the present study, the cognitive deficits induced by sleep deprivation were not extensive, as performance decreased in only two out of six tasks. This is somewhat surprising considering that previous studies suggest that sleep deprivation elicits deficits in various cognitive domains (Lim and Dinges, 2010). However, the null-effects on most of the tasks in our study might be a consequence of the rather small sample size. That is, our study might not have had sufficient statistical power to reveal small effects of the experimental manipulation (Open Science Collaboration, 2015). A power calculation with G*Power (Faul et al., 2009) revealed that we had a statistical power near 1.0 when searching for large effect sizes at an alpha of 0.05 , which decreased to $<0.80$ when searching for small effect sizes. Thus, the power in our study was sufficient to detect robust effects (as in the GNG and n-back tasks), but it was not sufficient to detect less robust effects as, for example, in the CPT.

Another explanation for the lack of significant effects on most measures could be that our manipulation was not strong enough. Longer periods of sleep deprivation (e.g., $32 \mathrm{~h}$ ) might have impaired 
cognitive functioning much more strongly (see, e.g., Harrison and Horne, 1997, 1998; Horne, 1988; Killgore et al., 2009). In line with this, Thomas et al. $(2000,2003)$ were able to show that activity decreases in certain brain regions (e.g., thalamus and prefrontal cortex) after $32 \mathrm{~h}$ of sleep deprivation become even stronger after sleep deprivation of 48 and $72 \mathrm{~h}$. Also, Drummond et al. (2006) found stronger decreases of inhibitory control after two nights compared to one night of sleep deprivation. However, several previous studies suggest that $24 \mathrm{~h}$ of sleep deprivation (as used in the present study) suffice to decrease cognitive performance (see, e.g., Chuah et al., 2006; Joo et al., 2012; Labelle et al., 2015; Petrovsky et al., 2014). Moreover, in the same sample reported here, we found effects of $24 \mathrm{~h}$ of sleep deprivation on oculomotor measures (Meyhöfer et al., 2017). It thus appears that our approach-although not as effective as expected-was justified. Nevertheless, future studies might consider implementing longer (and thus more effective) periods of sleep deprivation when investigating its potential as a state model system of psychosis.

\subsection{Effects of schizotypy}

We did not find any differences between the high and low schizotypy groups in cognitive performance. These results, therefore, do not provide strong support for the idea that schizotypy can serve as a model system of psychosis. At a first glance, these findings are at odds with a large number of studies reporting cognitive deficits in schizotypy (see, e.g., Chan et al., 2011; Giakoumaki, 2012) There are, however, several studies that did not reveal any cognitive impairments in highly schizotypal individuals (for meta-analyses, see Chun et al., 2013; Steffens et al., 2018).

The fact that neuropsychological deficits typically observed in schizophrenia are not reliably found in highly schizotypal individuals may thus cast doubt on the validity of schizotypy as a trait model system of psychosis. However, in several psychophysiological tasks, schizotypy is indeed quite reliably associated with deficits similar to those observed in schizophrenia. For example, studies consistently report eye movement dysfunctions in schizotypy, especially on antisaccade and smooth pursuit tasks (e.g., Ettinger et al., 2005; Holahan and O'Driscoll, 2005; Meyhöfer et al., 2017), resembling the pattern of impairments that is common in schizophrenia patients (Gooding and Basso, 2009; O'Driscoll and Callahan, 2008). Furthermore, highly schizotypal individuals consistently perform worse on tasks assessing prepulse inhibition, a measure of sensorimotor gating, again resembling deficits found in schizophrenia patients (Giakoumaki, 2012). It appears that functions more basal than the cognitive abilities measured in the present study may be impaired in subjects with high levels of schizotypy. This suggests that-rather than refuting the theory of schizotypy as a model system of psychosis-basic (motor or perceptual) biomarkers instead of more higher-level cognitive functions should be preferentially targeted. Fittingly, Chun et al. (2013) have recently questioned whether assessments of cognitive functioning adequately cover the deficits associated with schizotypy. It is worth mentioning that when combining trait model systems of psychosis with higher-level cognitive biomarkers of schizophrenia, there might be trait model systems more suitable than the schizotypy model system. For example, a recent meta-analysis by Giuliano et al. (2012) examined cognitive impairments in individuals with a putative psychosis prodrome at risk of developing schizophrenia. The authors reported mild cognitive deficits at an intermediate level between healthy controls and schizophrenia patients, with small to medium effect sizes for almost all investigated cognitive domains.

As pointed out in the introduction, schizophrenia patients can be divided into the cognitive deficit and the cognitively spared subtypes (Jablensky, 2006). In contrast to the cognitive deficit subtype, the cognitively spared subtype is characterized by just mild impairments of cognitive functions. Although it has never been examined, it is conceivable that this subtyping is valid not only for schizophrenia patients, but also for highly schizotypal individuals. As most of our participants had been college students, it would not be surprising if they pertained to the cognitively spared subtype. This possibility supports the previous suggestion of using more basic biomarkers instead of higher-level cognitive functions to investigate putative model systems of psychosis.

In previous reports of cognitive deficits in schizotypal individuals, these were mainly restricted to individuals with high scores on the positive dimension of schizotypy (see, e.g., Bergida and Lenzenweger, 2006; Ettinger et al., 2005; Holahan and O'Driscoll, 2005; Kaczorowski et al., 2009; Krabbendam et al., 2005). Accordingly, we focused on this dimension in the present study. However, negative schizotypy might also be associated with certain cognitive impairments; in fact, this association might even be stronger than the link with positive schizotypy in some domains. For example, working memory has been found to be associated mainly with negative schizotypy (Karagiannopoulou et al., 2016) and a recent meta-analysis found effects for negative, but not positive schizotypy in the updating dimension of cognitive control (Steffens et al., 2018). A stronger focus should also be on the disorganized dimension, which is often ignored in schizotypy research (Steffens et al., 2018). Although a recent meta-analysis (Steffens et al., 2018), did not find any effect of disorganized schizotypy on inhibition, there are studies reporting associations between schizotypy and cognitive control in the disorganized, but not in the positive or negative dimension (Kerns, 2006; Moritz et al., 1999). Thus, an extension of the present study design to two or three different schizotypy groups (positive, negative, disorganized) might be a promising avenue for future research to discover cognitive deficits in schizotypy.

Another limitation of our study design and possible explanation for missing effects of schizotypy might be that the cut-off scores for assignment to the schizotypy group were rather low, compared to other studies that applied thresholds of 1.5 or 2 SD above the mean (e.g., Gooding et al., 2006; Lenzenweger et al., 2000; Meyhöfer et al., 2015). However, our decision to apply a threshold of 1.25 SD above the mean was based on several studies that reported effects of schizotypy using the same or even lower cut-offs (e.g., Koychev et al., 2012; Tsakanikos and Claridge, 2005). Moreover, effects of schizotypy on measures of oculomotor control have been found in the same sample that was examined in the present study (Meyhöfer et al., 2017).

\subsection{Combined effects of sleep deprivation and schizotypy}

In addition to testing the primary effects of schizotypy and sleep deprivation, we explored whether the two model systems might be particularly effective when used in combination. That is, cognitive functioning in highly schizotypal individuals following sleep deprivation might most closely resemble cognitive performance of schizophrenia patients. However, we did not find any interaction effects. This suggests that combining the two model systems is not necessarily superior in terms of eliciting psychosis-like deficits than using only one of them. This conclusion contradicts a recent finding demonstrating that schizotypy and sleep deprivation indeed interact (Meyhöfer et al., 2017). Again, however, this latter finding was based on the assessment of oculomotor, rather than cognitive, biomarkers. This pattern corroborates our argument that measures of motor or perceptual functioning might be more sensitive to the influence of schizotypy and sleep deprivation, potentially making them more useful when studying model systems of psychosis.

An important question that we were not able to address properly is whether there are any gender differences that could have an impact on the interaction between schizotypy and sleep deprivation. In an additional analysis with gender as another factor (Supplementary Table 1) we did not find any interaction effects between gender, group and sleep deprivation. However, due to the very low number of male participants in the study, these results are highly inconclusive. The investigation of such gender effects with higher sample sizes of both male and female participants could be a valuable approach for future research. 


\subsection{Conclusions}

We provide further evidence for the hypothesis that sleep deprivation might serve as a state model system of psychosis, although this conclusion is restricted to the cognitive dimensions of inhibitory control and working memory and the findings should therefore be treated with caution. Our findings are less confirmative regarding the adequacy of schizotypy as a trait model system of psychosis with regards to cognitive biomarkers. Nevertheless, the idea of studying highly schizotypal individuals to better understand the pathophysiology of psychosis should not be rejected out of hand. We suggest that this hypothesis should be evaluated further by assessing more basal biomarkers of schizophrenia rather than complex cognitive deficits and/or extending the duration of sleep deprivation.

\section{Acknowledgements}

V.K. acknowledges receipt of a Humboldt Research Award. We thank Ann-Kathrin Arnold, Christian Burke, Eva Freda, Tristan Hencke, Linda Ludewigs, Hülya Öztürk, Marie Rundholz, Jörg Wester, and Yvonne Winter for their help in data collection. Furthermore, we thank all volunteers for participating in the study.

\section{Funding}

This research did not receive any specific grant from funding agencies in the public, commercial, or not-for-profit sectors.

\section{Declaration of interest}

The authors declare no conflict of interest.

\section{Ethical standards}

The authors assert that all procedures contributing to this work comply with the ethical standards of The Code of Ethics of the World Medical Association (Declaration of Helsinki). Informed consent was obtained from all participants.

\section{Supplementary materials}

Supplementary material associated with this article can be found, in the online version, at doi:10.1016/j.psychres.2018.10.033.

\section{References}

Acheson, A., Richards, J.B., de Wit, H., 2007. Effects of sleep deprivation on impulsive behaviors in men and women. Physiol. Behav. 91, 579-587. https://doi.org/10. 1016/j.physbeh.2007.03.020.

Ackenheil, M., Stotz, G., Dietz-Bauer, R., Vossen, A., 1999. Mini International Neuropsychiatric Interview. Psychiatrische Universitätsklinik München, München German version 5.0.0.

Aguirre, F., Sergi, M.J., Levy, C.A., 2008. Emotional intelligence and social functioning in persons with schizotypy. Schizophr. Res. 104, 255-264. https://doi.org/10.1016/j. schres.2008.05.007.

Aschenbrenner, S., Tucha, O., Lange, K.W., 2000. Regensburger Wortflüssigkeits-test. Hogrefe Verlag für Psychologie. Gottingen, Bern, Toronto, Seattle.

Bergida, H., Lenzenweger, M.F., 2006. Schizotypy and sustained attention: confirming evidence from an adult community sample. J. Abnorm. Psychol. 115, 545-551. https://doi.org/10.1037/0021-843X.115.3.545.

Boivin, D.B., 2000. Influence of sleep-wake and circadian rhythm disturbances in psychiatric disorders. J. Psychiatry Neurosci. 25, 446-458.

Callicott, J., Ramsey, N., Tallent, K., Bertolino, A., Knable, M., Coppola, R., Goldberg, T., van Gelderen, P., Mattay, V., Frank, J., Moonen, C., Weinberger, D., 1998. Functional magnetic resonance imaging brain mapping in psychiatry: methodological issues illustrated in a study of working memory in schizophrenia. Neuropsychopharmacology 18, 186-196. https://doi.org/10.1016/s0893-133x(97)00096-1.

Callicott, J.H., Mattay, V.S., Verchinski, B.A., Marenco, S., Egan, M.F., Weinberger, D.R., 2003. Complexity of prefrontal cortical dysfunction in schizophrenia: more than up or down. Am. J. Psychiatry 160, 2209-2215. https://doi.org/10.1176/appi.ajp.160. 12.2209 .
Chan, R.C.K., Wang, Y., Yan, C., Song, L., Wang, Y., Shi, Y., Gong, Q., Cheung, E.F.C., 2011. Contribution of specific cognitive dysfunction to people with schizotypal personality. Psychiatry Res. 186, 71-75. https://doi.org/10.1016/j.psychres.2010. 06.016.

Chee, M.W.L., Chuah, L.Y.M., Venkatraman, V., Chan, W.Y., Philip, P., Dinges, D.F., 2006. Functional imaging of working memory following normal sleep and after 24 and 35h of sleep deprivation: correlations of fronto-parietal activation with performance. Neuroimage 31, 419-428. https://doi.org/10.1016/j.neuroimage.2005.12.001.

Choo, W., Lee, W., Venkatraman, V., Sheu, F., Chee, M.W.L., 2005. Dissociation of cortical regions modulated by both working memory load and sleep deprivation and by sleep deprivation alone. Neuroimage 25, 579-587. https://doi.org/10.1016/j.neuroimage. 2004.11.029.

Chuah, Y.M.L., Venkatraman, V., Dinges, D.F., Chee, M.W.L., 2006. The neural basis of interindividual variability in inhibitory efficiency after sleep deprivation. J. Neurosci. 26, 7156-7162. https://doi.org/10.1523/JNEUROSCI.0906-06.2006.

Chun, C.A., Minor, K.S., Cohen, A.S., 2013. Neurocognition in psychometrically defined college schizotypy samples: we are NOT measuring the "right stuff". J. Int. Neuropsychol. Soc. 19, 324-337. https://doi.org/10.1017/S135561771200152X.

Cohen, J., 1973. Eta-squared and partial eta-squared in fixed factor anova designs. Educ. Psychol. Meas. 33, 107-112. https://doi.org/10.1177/001316447303300111.

Corlett, P.R., Honey, G.D., Fletcher, P.C., 2016. Prediction error, ketamine and psychosis : an updated model. J. Psychopharmacol. 30, 1145-1155. https://doi.org/10.1177/ 0269881116650087.

Cornblatt, B.A., Risch, N.J., Faris, G., Friedman, D., Erlenmeyer-Kimling, L., 1988. The continuous performance test, identical pairs version (CPT-IP): I. New findings about sustained attention in normal families. Psychiatry Res. 26, 223-238. https://doi.org/ 10.1016/0165-1781(88)90076-5.

Diforio, D., Walker, E.F., Kestler, L.P., 2000. Executive functions in adolescents with schizotypal personality disorder. Schizophr. Res. 42, 125-134. https://doi.org/10 1016/s0920-9964(99)00119-x.

Drummond, S.P.A., Brown, G.G., Gillin, J.C., 2000. Altered brain response to verbal learning following sleep deprivation. Nature 403, 655-657. https://doi.org/10.1038/ 35001068.

Drummond, S.P.A., Paulus, M.P., Tapert, S.F., 2006. Effects of two nights sleep deprivation and two nights recovery sleep on response inhibition. J. Sleep Res. 15, 261-265. https://doi.org/10.1111/j.1365-2869.2006.00535.x.

Ettinger, U., Aichert, D.S., Wöstmann, N., Dehning, S., Riedel, M., Kumari, V., 2017. Response inhibition and interference control: effects of schizophrenia, genetic risk, and schizotypy. J. Neuropsychol. 12, 484-510. https://doi.org/10.1111/jnp.12126.

Ettinger, U., Kumari, V., 2015. Effects of sleep deprivation on inhibitory biomarkers of schizophrenia: implications for drug development. Lancet Psychiatry 2, 1028-1035. https://doi.org/10.1016/s2215-0366(15)00313-2.

Ettinger, U., Kumari, V., Crawford, T.J., Flak, V., Sharma, T., Davis, R.E., Corr, P.J., 2005 Saccadic eye movements, schizotypy, and the role of neuroticism. Biol. Psychol. 68, 61-78. https://doi.org/10.1016/j.biopsycho.2004.03.014.

Ettinger, U., Meyhöfer, I., Steffens, M., Wagner, M., Koutsouleris, N., 2014. Genetics, cognition, and neurobiology of schizotypal personality: a review of the overlap with schizophrenia. Front. Psychiatry 5, 1-16. https://doi.org/10.3389/fpsyt.2014.00018.

Ettinger, U., Williams, S.C.R., Fannon, D., Premkumar, P., Kuipers, E., Möller, H.J., Kumari, V., 2011. Functional magnetic resonance imaging of a parametric working memory task in schizophrenia: relationship with performance and effects of antipsychotic treatment. Psychopharmacology (Berl) 216, 17-27. https://doi.org/10. 1007/s00213-011-2214-7.

Ettinger, U., Williams, S.C.R., Meisenzahl, E.M., Möller, H.-J., Kumari, V., Koutsouleris, N., 2012. Association between brain structure and psychometric schizotypy in healthy individuals. World J. Biol. Psychiatry 13, 544-549. https://doi.org/10.3109/ 15622975.2011.559269.

Faul, F., Erdfelder, E., Buchner, A., Lang, A., 2009. Statistical power analyses using $\mathrm{G}^{*}$ Power 3.1: tests for correlation and regression analyses. Behav. Res. Methods 41 , 1149-1160. https://doi.org/10.3758/BRM.41.4.1149.

Fioravanti, M., Bianchi, V., Cinti, M.E., 2012. Cognitive deficits in schizophrenia: an updated metanalysis of the scientific evidence. BMC Psychiatry 12,1-20. https://doi. org/10.1186/1471-244x-12-64.

Friedman, N.P., Miyake, A., 2004. The relations among inhibition and interference control functions : a latent-variable analysis. J. Exp. Psychol. 133, 101-135. https://doi. org/10.1037/0096-3445.133.1.101.

Giakoumaki, S.G., 2012. Cognitive and prepulse inhibition deficits in psychometrically high schizotypal subjects in the general population: relevance to schizophrenia research. J. Int. Neuropsychol. Soc. 18, 643-656. https://doi.org/10.1017/ S135561771200029X.

Giuliano, A., Li, H., Mesholam-Gately, R., M. Sorenson, S., A. Woodberry, K., J. Seidman, L., 2012. Neurocognition in the psychosis risk syndrome: a quantitative and qualitative review. Curr. Pharm. Des. 18, 399-415. https://doi.org/10.2174/ 138161212799316019.

Glass, G.V, 1966. Testing homogeneity of variances. Am. Educ. Res. J. 3, 187-190. https://doi.org/10.3102/00028312003003187.

Gooding, D.C., Basso, M.A., 2009. The tell-tale tasks: a review of saccadic research in psychiatric patient populations. Brain Cogn. 68, 371-390. https://doi.org/10.1016/j bandc.2008.08.024. The.

Gooding, D.C., Matts, C.W., Rollmann, E.A., 2006. Sustained attention deficits in relation to psychometrically identified schizotypy: evaluating a potential endophenotypic marker. Schizophr. Res. 82, 27-37. https://doi.org/10.1016/j.schres.2005.11.015.

Grant, P., Kuepper, Y., Mueller, E.A., Wielpuetz, C., Mason, O.J., Hennig, J., 2013. Dopaminergic foundations of schizotypy as measured by the German version of the Oxford-Liverpool Inventory of Feelings and Experiences (O-LIFE)-a suitable endophenotype of schizophrenia. Front. Hum. Neurosci. 7, 1. https://doi.org/10.3389/ 
fnhum.2013.00001.

Habeck, C., Rakitin, B.C., Moeller, J., Scarmeas, N., Zarahn, E., Brown, T., Stern, Y., 2004. An event-related fMRI study of the neurobehavioral impact of sleep deprivation on performance of a delayed-match-to-sample task. Cogn. Brain Res. 18, 306-321. https://doi.org/10.1016/j.cogbrainres.2003.10.019.

Harrison, Y., Horne, J.A., 1997. Sleep deprivation affects speech. Sleep 20 871-877. https://doi.org/10.1093/sleep/20.10.871.

Harrison, Y., Horne, J.A., 1998. Sleep loss impairs short and novel language tasks having a prefrontal focus. J. Sleep Res. 7, 95-100. https://doi.org/10.1046/j.1365-2869. 1998.00104.x.

Heinrichs, R.W., Zakzanis, K.K., 1998. Neurocognitive deficit in schizophrenia: a quantitative review of the evidence. Neuropsychology 12, 426-445. https://doi.org/10. 1037//0894-4105.12.3.426.

Holahan, A.L.V, O'Driscoll, G.A., 2005. Antisaccade and smooth pursuit performance in positive- and negative-symptom schizotypy. Schizophr. Res. 76, 43-54. https://doi. org/10.1016/j.schres.2004.10.005.

Holm, S., 1979. A simple sequentially rejective multiple test procedure. Scand. J. Stat. 6, 65-70.

Horne, J.A., 1988. Sleep loss and "divergent" thinking ability. Sleep 11, 528-536. https:// doi.org/10.1093/sleep/11.6.528.

Ikegami, K.I., Ogyu, S., Arakomo, Y., Suzuki, K., Mafune, K., Hiro, H., Nagata, S., 2009. Recovery of cognitive performance and fatigue after one night of sleep deprivation. J. Occup. Health 51, 412-422. https://doi.org/10.1539/joh.18127.

Jablensky, A., 2006. Subtyping schizophrenia: implications for genetic research. Mol. Psychiatry 11, 815-836. https://doi.org/10.1038/sj.mp.4001857.

Jennings, J.R., 1987. Editorial policy on analyses of variance with repeated measures. Psychophysiology 24, 474-475. https://doi.org/10.1111/j.1469-8986.1987. tb00320.x.

Joo, E.Y., Yoon, C.W., Koo, D.L., Kim, D., Hong, S.B., 2012. Adverse effects of 24 hours of sleep deprivation on cognition and stress hormones. J. Clin. Neurol. 8, 146-150. https://doi.org/10.3988/jcn.2012.8.2.146.

Kaczorowski, J.A., Barrantes-vidal, N., Kwapil, T.R., 2009. Neurological soft signs in psychometrically identified schizotypy. Schizophr. Res. 115, 293-302. https://doi. org/10.1016/j.schres.2009.06.018.

Karagiannopoulou, L., Karamaouna, P., Zouraraki, C., Bitsios, P., Giakoumaki, S.G., 2016. Cognitive profiles of schizotypal dimensions in a community cohort: common properties of differential manifestations. J. Clin. Exp. Neuropsychol. 38, 1050-1063. https://doi.org/10.1080/13803395.2016.1188890.

Karlsson, A.U., Nilsson, J.P., So, M., 2005. Less effective executive functioning after one night's sleep deprivation. J. Sleep Res. 14, 1-6. https://doi.org/10.1111/j.13652869.2005.00442.x.

Kempton, M.J., Ettinger, U., Foster, R., Williams, S.C.R., Calvert, G.A., Hampshire, A., Zelaya, F.O., Gorman, R.L.O., Mcmorris, T., Owen, A.M., Smith, M.S., 2011. Dehydration affects brain structure and function in healthy adolescents. Hum. Brain Mapp. 32, 71-79. https://doi.org/10.1002/hbm.20999.

Kerns, J.G., 2006. Schizotypy facets, cognitive control, and emotion. J. Abnorm. Psychol. 115, 418-427. https://doi.org/10.1037/0021-843X.115.3.418.

Kerns, J.G., Becker, T.M., 2008. Communication disturbances, working memory, and emotion in people with elevated disorganized schizotypy. Schizophr. Res. 100, 172-180. https://doi.org/10.1016/j.schres.2007.11.005.

Kiehl, K.A., Smith, A.M., Hare, R.D., Liddle, P.F., 2000. An event-related potential investigation of response inhibition in schizophrenia and psychopathy. Biol. Psychiatry 48, 210-221. https://doi.org/10.1016/s0006-3223(00)00834-9.

Killgore, W.D.S., Kahn-Greene, E.T., Grugle, N.L., Killgore, D.B., Balkin, T.J., 2009. Sustaining executive functions during sleep deprivation: a comparison of caffeine, dextroamphetamine, and modafinil. Sleep 32, 205-216. https://doi.org/10.1093/ sleep/32.2.205.

Kopasz, M., Loessl, B., Hornyak, M., Riemann, D., Nissen, C., Piosczyk, H., Voderholzer, U., 2010. Sleep and memory in healthy children and adolescents-a critical review. Sleep Med. Rev. 14, 167-177. https://doi.org/10.1016/j.smrv.2009.10.006.

Koychev, I., Barkus, E., Ettinger, U., Killcross, S., Roiser, J.P., Wilkinson, L., Deakin, B. 2011. Evaluation of state and trait biomarkers in healthy volunteers for the development of novel drug treatments in schizophrenia. J. Psychopharmacol. 25, 1207-1225. https://doi.org/10.1177/0269881111414450.

Koychev, I., Joyce, D., Barkus, E., Ettinger, U., Schmechtig, A., Dourish, C.T., Dawson, G.R., Craig, K.J., Deakin, J.F.W., 2016. Cognitive and oculomotor performance in subjects with low and high schizotypy: implications for translational drug development studies. Transl. Psychiatry 6, e811. https://doi.org/10.1038/tp.2016.64.

Koychev, I., McMullen, K., Lees, J., Dadhiwala, R., Grayson, L., Perry, C., Schmechtig, A., Walters, J., Craig, K.J., Dawson, G.R., Dourish, C.T., Ettinger, U., Wilkinson, L., Williams, S., Deakin, J.F.W., Barkus, E., 2012. A validation of cognitive biomarkers for the early identification of cognitive enhancing agents in schizotypy: a three-center double- blind placebo-controlled study. Eur. Neuropsychopharmacol. 22, 469-481. https://doi.org/10.1016/j.euroneuro.2011.10.005.

Krabbendam, L., Myin-Germeys, I., Hanssen, M., van Os, J., 2005. Familial covariation of the subclinical psychosis phenotype and verbal fluency in the general population. Schizophr. Res. 74, 37-41. https://doi.org/10.1016/j.schres.2004.08.009.

Krieger, S., Lis, S., Cetin, T., Gallhofer, B., Meyer-Lindenberg, A., 2005. Drug-Naive schizophrenia: an analysis of N-back performance. Am. J. Psychiatry 162, 1206-1208.

Kumari, V., Antonova, E., Geyer, M.A., 2008. Prepulse inhibition and "psychosis-proneness" in healthy individuals: an fMRI study. Eur. Psychiatry 23, 274-280. https://doi. org/10.1016/j.eurpsy.2007.11.006.

Kumari, V., Antonova, E., Geyer, M.A., Ffytche, D., Williams, S.C.R., Sharma, T., 2007. A fMRI investigation of startle gating deficits in schizophrenia patients treated with typical or atypical antipsychotics. Int. J. Neuropsychopharmacol. 10, 463-477.
https://doi.org/10.1017/S1461145706007139.

Labelle, M., Dang-Vu, T.T., Zadra, A., 2015. Sleep deprivation impairs inhibitory control during wakefulness in adult sleepwalkers. J. Sleep Res. 24, 658-665. https://doi.org/ 10.1111/jsr.12315

Langdon, R., Coltheart, M., 1999. Mentalising, schizotypy, and schizophrenia. Cognition 71, 43-71. https://doi.org/10.1016/s0010-0277(99)00018-9.

Laws, K.R., Kondel, T.K., Clarke, R., Nillo, A., 2011. Delusion-prone individuals: stuck in their ways? Psychiatry Res. 186, 219-221. https://doi.org/10.1016/j.psychres.2010. 09.018 .

Lehrl, S., 2005. Mehrfachwahl-Wortschatz-Intelligenztest MWT-B. Spitta Verlag, Balingen.

Lenzenweger, M.F., 2001. Reaction time slowing during high-load, sustained-attention task performance in relation to psychometrically identified schizotypy. J. Abnorm Psychol. 110, 290-296. https://doi.org/10.1037//0021-843X.110.2.290.

Lenzenweger, M.F., Gold, J.M., 2000. Auditory working memory and verbal recall memory in schizotypy. Schizophr. Res. 42, 101-110. https://doi.org/10.1016/s09209964(99)00121-8.

Liddle, P.F., 1987. The symptoms of chronic schizophrenia. A re-examination of the positive-negative dichotomy. Br. J. Psychiatry 151, 145-151. https://doi.org/10.1192/ bjp.151.2.145.

Lim, J., Dinges, D.F., 2010. A meta-analysis of the impact of short-term sleep deprivation on cognitive variables. Psychol. Bull. 136, 375-389. https://doi.org/10.1037/ a0018883.

Lipszyc, J., Schachar, R., 2010. Inhibitory control and psychopathology: a meta-analysis of studies using the stop signal task. J. Int. Neuropsychol. Soc. 16, 1064-1076. https://doi.org/10.1017/s1355617710000895.

Mason, O.J., Morgan, C.J.M., Stefanovic, A., Curran, H.V., 2008. The Psychotomimetic States Inventory (PSI): measuring psychotic-type experiences from ketamine and cannabis. Schizophr. Res. 103, 138-142. https://doi.org/10.1016/j.schres.2008.02. 020.

Matheson, S., Langdon, R., 2008. Schizotypal traits impact upon executive working memory and aspects of IQ. Psychiatry Res. 159, 207-214. https://doi.org/10.1016/j. psychres.2007.04.006.

Mesholam-Gately, R.I., Giuliano, A.J., Goff, K.P., Faraone, S.V, Seidman, L.J., 2009. Neurocognition in first-episode schizophrenia: a meta-analytic review. Neuropsychology 23, 315-336. https://doi.org/10.1037/a0014708.

Meyhöfer, I., Kumari, V., Hill, A., Petrovsky, N., 2016. Sleep deprivation as an experimental model system for psychosis: effects on smooth pursuit, prosaccades, and antisaccades. J. Psychopharmacol. 31, 418-433. https://doi.org/10.1177/ 0269881116675511.

Meyhöfer, I., Steffens, M., Faiola, E., Kasparbauer, A.-M., Kumari, V., Ettinger, U., 2017 Combining two model systems of psychosis: The effects of schizotypy and sleep deprivation on oculomotor control and psychotomimetic states. Psychophysiology 54, 1-15. https://doi.org/10.1111/psyp.12917.

Meyhöfer, I., Steffens, M., Kasparbauer, A., Grant, P., Weber, B., Ettinger, U., 2015. Neural mechanisms of smooth pursuit eye movements in schizotypy. Hum. Brain Mapp. 36, 340-353. https://doi.org/10.1002/hbm.22632.

Minzenberg, M.J., Laird, A.R., Thelen, S., Carter, C.S., Glahn, D.C., 2009. Meta-analysis of 41 functional neuroimaging studies of executive function in schizophrenia. Arch. Gen. Psychiatry 66, 811-822. https://doi.org/10.1001/archgenpsychiatry.2009.91.

Moritz, S., Andresen, B., Naber, D., Krausz, M., Probsthein, E., 1999. Neuropsychological correlates of schizotypal disorganisation. Cogn. Neuropsychiatry 4, 343-349. https:// doi.org/10.1080/135468099395873.

Mu, Q., Mishory, A., Johnson, K.A., Nahas, Z., Kozel, F.A., Yamanaka, K., Bohning, D.E., George, M.S., 2005. Decreased brain activation during a working memory task at rested baseline is associated with vulnerability to sleep deprivation. Sleep 28, 433-448. https://doi.org/10.1093/sleep/28.4.433.

Murray, R.M., Paparelli, A., Morrison, P.D., Marconi, A., Di Forti, M., 2013. What can we learn about schizophrenia from studying the human model, drug-induced psychosis ? Am. J. Med. Genet. 162 661-170. https://doi.org/10.1002/ajmg.b.32177.

Nelson, M.T., Seal, M.L., Pantelis, C., Phillips, L.J., 2013. Evidence of a dimensional relationship between schizotypy and schizophrenia: a systematic review. Neurosci. Biobehav. Rev. 37, 317-327. https://doi.org/10.1016/j.neubiorev.2013.01.004.

Niemann, H., Sturm, W., Thöne-Otto, A.I.T., Willmes, K., 2008. California Verbal Learning Test: Deutschsprachige Adaptation. Pearson Assessment \& Information GmbH, Frankfurt am Main.

Obiols, J.E., Serrano, F., Caparros, B., Subira, S., 1999. Neurological soft signs in adolescents with poor performance on the continuous performance test: markers of liability for schizophrenia spectrum disorders ? Psychiatry Research 86, 217-228. https://doi.org/10.1016/s0165-1781(99)00039-6.

O'Driscoll, G.A., Callahan, B.L., 2008. Smooth pursuit in schizophrenia: a meta-analytic review of research since 1993. Brain Cogn 68, 359-370. https://doi.org/10.1016/j. bandc.2008.08.023.

Olesen, P.J., Westerberg, H., Klingberg, T., 2004. Increased prefrontal and parietal activity after training of working memory. Nat. Neurosci. 7, 75-79. https://doi.org/10. 1038/nn1165.

Open Science Collaboration, 2015. Estimating the reproducibility of psychological science. Science 80 (349) aac4716. https://doi.org/10.1126/science.aac4716.

Palacio, P.M., Navarro, J.B., Pradas, C.M., Yeste, I.B., Sabanés, A., Vilanova, J.V., Álvarez, E.M., Vidal, N.B., Subirá, S., 2006. Esquizotipia y memoria verbal en población general adolescente. Psicothema 18, 439-446.

Perlstein, W.M., Dixit, N.K., Carter, C.S., Noll, D.C., Cohen, J.D., 2003. Prefrontal cortex dysfunction mediates deficits in working memory and prepotent responding in schizophrenia. Biol. Psychiatry 53, 25-38. https://doi.org/10.1016/s0006-3223(02) 01675-X.

Pessoa, L., Gutierrez, E., Bandettini, P., Ungerleider, L., 2002. Neural correlates of visual 
working memory: fMRI amplitude predicts task performance. Neuron 35, 975-987. https://doi.org/10.1016/S0896-6273(02)00817-6.

Peters, E.R., Pickering, A.D., Hemsley, D.R., 1994. Cognitive inhibition and positive symptomatology in schizotypy. Br. J. Clin. Psychol. 33, 33-48. https://doi.org/10. 1111/j.2044-8260.1994.tb01092.x.

Petrovsky, N., Ettinger, U., Hill, A., Frenzel, L., Meyhöfer, I., Wagner, M., Backhaus, J., Kumari, V., 2014. Sleep deprivation disrupts prepulse inhibition and induces psychosis-like symptoms in healthy humans. J. Neurosci. 34, 9134-9140. https://doi. org/10.1523/JNEUROSCI.0904-14.2014.

Schaefer, J., Giangrandea, E., Weinberger, D.R., Dickinson, D., 2013. The global cognitive impairment in schizophrenia: consistent over decades and around the world. Schizophr. Res. 150, 42-50. https://doi.org/10.1016/j.schres.2013.07.009.The.

Shallice, T., 1982. Specific impairment in planning. Philos. Trans. R. Soc. Lond. 298, 199-209. https://doi.org/10.1098/rstb.1982.0082.

Shapiro, A.S.S., Wilk, M.B., 1965. An analysis of variance test for normality (complete samples). Biometrika 52, 591-611. https://doi.org/10.1093/biomet/52.3-4.591.

Shenton, M.E., Shenton, M.E., Dickey, C.C., Dickey, C.C., Frumin, M., Frumin, M., Mccarley, R.W., Mccarley, R.W., 2001. A review of MRI ndings in schizophrenia. Schizophr. Res. 49, 1-52. https://doi.org/10.1016/s0920-9964(01)00163-3.

Shepherd, A.M., Laurens, K.R., Matheson, S.L., Carr, V.J., Green, M.J., 2012. Systematic meta-review and quality assessment of the structural brain alterations in schizophrenia. Neurosci. Biobehav. Rev. 36, 1342-1356. https://doi.org/10.1016/j. neubiorev.2011.12.015.

Smith, M.E., Mcevoy, L.K., Gevins, A., 2002. The impact of moderate sleep loss on neurophysiologic signals during working- memory task performance. Sleep 25, 56-66. https://doi.org/10.1093/sleep/25.7.56.

Snitz, B.E., Macdonald III, A.W., Carter, C.S., 2006. Cognitive deficits in unaffected firstdegree relatives of schizophrenia patients: a meta-analytic review of putative endophenotypes. Schizophr. Bull. 32, 179-194. https://doi.org/10.1093/schbul/ sbi048.

Steffens, M., Meyhöfer, I., Fassbender, K., Ettinger, U., Kambeitz, J., 2018. Association of schizotypy with dimensions of cognitive control: a meta-analysis. Schizophr. Bull. 44,
S512-S524. https://doi.org/10.1093/schbul/sby030.

Thomas, M.L., Sing, H.C., Belenky, G., Holcomb, H.H., Mayberg, H.S., Dannals, R.F. Wagner, H.N., Thorne, D.R., Popp, K.A., Rowland, L.M., Welsh, A.B., Balwinski, S.M., Redmond, D.P., 2000. Neural basis of alertness and cognitive performance impairments during sleepiness: I. Effects of $24 \mathrm{~h}$ of sleep deprivation on waking human regional brain activity. J. Sleep Res. 9, 335-352. https://doi.org/10.1016/S14729288(03)00020-7.

Thomas, M.L., Sing, H.C., Belenky, G., Holcomb, H.H., Mayberg, H.S., Dannals, R.F., Wagner, H.N., Thorne, D.R., Popp, K.a., Rowland, L.M., Welsh, A.B., Balwinski, S.M., Redmond, D.P., 2003. Neural basis of alertness and cognitive performance impairments during sleepiness: II. Effects of 48 and $72 \mathrm{~h}$ of sleep deprivation on waking human regional brain activity. Thalamus Relat. Syst. 2, 199-229. https://doi.org/10 $1017 /$ s1472928803000207.

Tsakanikos, E., Claridge, G., 2005. More words, less words: Verbal fluency as a function of "positive" and "negative" schizotypy. Pers. Indiv. Dif. 39, 705-713. https://doi.org/ 10.1016/j.paid.2005.02.019.

van der Wee, N.J.A., Ramsey, N.F., Jansma, J.M., Denys, D.A., van Megen, H.J.G.M., Westenberg, H.M.G., Kahn, R.S., 2003. Spatial working memory deficits in obsessive compulsive disorder are associated with excessive engagement of the medial frontal cortex. Neuroimage 20, 2271-2280. https://doi.org/10.1016/j.neuroimage.2003.05. 001.

Wager, T.D., Sylvester, C.Y.C., Lacey, S.C., Nee, D.E., Franklin, M., Jonides, J., 2005. Common and unique components of response inhibition revealed by fMRI. Neuroimage 27, 323-340. https://doi.org/10.1016/j.neuroimage.2005.01.054.

Wickelgren, W.A., 1977. Speed-accuracy tradeoff and information processing dynamics. Acta Psychol. (Amst). 41, 67-85. https://doi.org/10.1016/0001-6918(77)90012-9.

Wright, L., Lipszyc, J., Dupuis, A., Thayapararajah, S.W., Schachar, R., 2014. Response inhibition and psychopathology: a meta-analysis of Go/No-Go task performance. J. Abnorm. Psychol. 123, 429-439. https://doi.org/10.1037/a0036295.

Wulff, K., Dijk, D.J., Middleton, B., Foster, R.G., Joyce, E.M., 2012. Sleep and circadian rhythm disruption in schizophrenia. Br. J. Psychiatry 200, 308-316. https://doi.org/ 10.1192/bjp.bp.111.096321. 